\title{
AUDIODESCRIÇÃO DO DESENHO ANIMADO PEPPA PIG: RELATO DE UMA EXPERIÊNCIA COM CRIANÇAS COM DEFICIÊNCIA VISUAL
}

\author{
Audio description of Peppa Pig cartoons: report of an experience with children with \\ visual impairment
}

\section{Audiodescripción del diseño animado Peppa Pig: relato de una experiencia con niños con discapacidad visual}

Andréia Paiva de Araújo Ferreira*

\section{Resumo}

Este estudo consiste na audiodescrição do desenho animado Peppa Pig, relatando a experiência do processo de elaboração do roteiro e suas etapas até a exibição para crianças com deficiência visual em uma escola. Objetivamos apresentar as informações importantes para elaboração de uma audiodescrição direcionada ao público infantil, a consultoria realizada por profissional com deficiência visual, a narração e a finalização do desenho com o recurso. A experiência profissional da pesquisadora como audiodescritora e como atriz e as reflexões sobre o processo auxiliaram na construção de uma proposta de audiodescrição para desenhos animados. A audiodescrição é uma importante ferramenta de acesso aos conteúdos imagéticos do desenho. O trabalho demonstra a relevância do conhecimento sobre o recurso e o acesso a desenhos animados, como meio de interação e inclusão à cultura.

PALAVRAS-CHAVE: Audiodescrição. Desenho Animado. Crianças. Deficiência Visual

\begin{abstract}
This study consists of the audio description of Peppa Pig cartoons, reporting the experience of elaborated the audio description script, its different phases until the cartoon's exhibition to the visually impaired children in a school. The main goal is to presente important information to make an audio description aimed at children public, the consulting that was made by a visually impaired professional, the narrative and a completion of the cartoon with the resource. The professional experience of the researcher as an audio describer and as an actress and the reflections about the process helped on a proposal construction for the audio description of cartoons. The audio description is an important tool to access the images contents of the cartoon. The work indicates the relevance of the knowledge about the resource and the access of cartoons, as a means of interaction and inclusion to the culture.
\end{abstract}

KEYWORDS: Audio Description. Cartoon. Children. Visual Impairment

\section{Resumen}

Este estudio consiste en la audiodescripción del dibujo animado Peppa Pig, relatando la experiencia del proceso de elaboración del guión y sus etapas hasta la exhibición para niños con discapacidad visual en una escuela. El objetivo de presentar las informaciones importantes para la confección de una audiodescripción dirigida al público infantil, la consultoría realizada por profesional con

\footnotetext{
* Especialista em audiodescrição pela Universidade Federal de Juiz de Fora (UFJF). Graduada em Psicologia pela Universidade Mackenzie. Atriz pelo Teatro escola Macunaíma- São Paulo. Email: psi.andreiaf@gmail.com.
}

Educação e Fronteiras On-Line, Dourados/MS, v.10, n.28, p.103-113, jan./abr. 2020 
deficiencia visual, la narración realizada por un profesional de la voz y la finalización del diseño con el recurso. La audiodescripción es una importante herramienta de acceso a los contenidos imagéticos del diseño. El trabajo apunta a la relevancia del conocimiento sobre el recurso y el acceso a dibujos animados, como medio de interacción e inclusión a la cultura.

PALABRAS ClAVE: Audiodescripción. Dibujo Animado. Los Niños. Deficiencia Visual

\title{
INTRODUÇÃO
}

Os desenhos animados são muito dinâmicos e possuem um grande apelo visual, o que faz com que sejam inacessíveis às crianças com deficiência visual, que ficam excluídas do acesso às imagens pela ausência de ferramenta de acessibilidade. Nosso cotidiano, desde a infância, é marcado pelo referencial imagético em propagandas veiculadas pela TV, internet, jornais, revistas, catálogos, livros, smartphones, tablets, computadores, entre outros tipos de tecnologia. As imagens podem nos informar, entreter-nos, chamar nossa atenção, despertar nossa curiosidade. Elas servem como ponto de partida para revelar, divulgar, informar, criticar, denunciar ou apenas ilustrar algo, sendo complementadas ou não com palavras.

Portanto, a questão que colocamos é: como as pessoas com deficiência visual acessam a cultura, como assistem à televisão, aos filmes, desenhos, shows, ou vão a museus e exposições?

O estatuto da criança e adolescente prevê a garantia do direito de acesso à cultura ao lazer: "Art.71 - A criança e o adolescente têm direito à informação, cultura, lazer, esportes, diversões, espetáculos e produtos e serviços que respeitem sua condição peculiar de pessoas em desenvolvimento" (2008, p.52).

De acordo com Motta e Filho (2010):

\begin{abstract}
A audiodescrição é um recurso de acessibilidade que amplia o entendimento das pessoas com deficiência visual em eventos culturais, gravados ou ao vivo, como: peças de teatro, programas de TV, exposições, mostras, musicais, óperas, desfiles e espetáculos de dança; eventos turísticos, esportivos, pedagógicos e científicos tais como aulas, seminários, congressos, palestras, feiras e outros, por meio de informação sonora. É uma atividade de mediação linguística, uma modalidade de tradução intersemiótica, que transforma o visual em verbal, abrindo possibilidades maiores de acesso à cultura e à informação, contribuindo para a inclusão cultural, social e escolar. Além das pessoas com deficiência visual, a audiodescrição amplia também o entendimento de pessoas com deficiência intelectual, idosos e disléxicos. (MOTTA; ROMEU FILHO, 2010, p. 11).
\end{abstract}

A audiodescrição (AD) é uma tradução em palavras do conteúdo imagético relevante de uma obra cultural. A pessoa cega ou com baixa visão complementa seu entendimento, equiparando aos estímulos de uma pessoa que enxerga. Desta maneira, ela receberá informações que a ajudarão a compreender o conteúdo da imagem. $\mathrm{O}$ audiodescritor/roteirista transpõe o visual para o verbal, comunica as imagens por palavras.

$\mathrm{Na}$ audiodescrição, precisamos perseguir a objetividade, embora não seja possível ter um olhar completamente neutro, desprovido de lente subjetiva. Cada audiodescritor traz para o roteiro seus conceitos e significados e isso interfere na forma de olhar o mundo. A maneira de "enxergar" e interpretar o mundo é diferente para cada um, assim como cada um é único e 
aprende de maneiras diferentes, sempre partindo de suas vivências. Descrever requer cuidado, experiência de vida, conhecimento geral e disponibilidade para pesquisa.

Para elaborar um roteiro de audiodescrição, o audiodescritor deve fazer um estudo da obra, personagens, características físicas, o papel de cada um na história, figurinos e cenário, saber para que público é destinado e o tipo de narração adequado ao gênero da obra. O roteiro deve ser objetivo, claro e sem muitas inferências ou subjetivações do roteirista. Sendo assim, o espectador com deficiência poderá retirar do texto suas próprias interpretações e seus próprios significados sobre o que acabou de assistir/ouvir. A pessoa com deficiência tem a possibilidade de criar seus próprios conceitos assistindo a um filme com audiodescrição. No entanto, cada audiodescritor/roteirista irá elaborar o roteiro para um mesmo filme, documentário ou desenho animado de forma diferente. Assim como temos várias versões traduzidas de um mesmo livro, podemos ter mais de uma versão de um produto cultural com audiodescrição, beneficiando os leitores e usuários do recurso.

Destacamos a relevância da $\mathrm{AD}$ como um caminho para o acesso à cultura, viabilizando a fruição de uma obra, propiciando inclusão e autonomia, quando "emprestamos" nossos olhos para aqueles que não enxergam ou não consigam ver um filme, uma peça de teatro, um quadro em um museu, entre outros.

A importância do recurso para pessoas com deficiência visual é evidente quando ouvimos depoimentos deste público após apresentações com audiodescrição. Cristiana Cerchiari, que possui deficiência visual, relatou sua experiência no livro Audiodescrição: transformando imagens em palavras, ao assistir à peça, $O$ andaime, com o recurso. "Foram momentos mágicos, que abriram novos espaços no meu rico mundo de quem nunca enxergou" (MOTTA, 2010. p. 207).

Em outro depoimento inserido no mesmo livro, Tobias enfatiza que a audiodescrição permitiu uma interpretação própria da peça, destacando também que a $\mathrm{AD}$ não é uma reprodução de todas as imagens, e sim dos elementos visuais relevantes para o entendimento.

De acordo com Tobias (2010):

\begin{abstract}
“(...) os audiodescritores me faziam ver o que eu não podia e ouvir o que não estava sendo dito verbalmente, mas pela linguagem gestual, pela expressão corporal, pela emoção estampada no rosto dos atores. E eu ia curtindo cada momento. Evidentemente, nem tudo que acontece em cena pode ser descrito em tempo real, senão atrapalha, sobrepõe a fala dos personagens. Mas como o verdadeiro artista sempre simplifica, e para mim a audiodescrição é uma arte, de forma simples e direta eles faziam chegar aos meus fones de ouvido o essencial para compor o meu entendimento" (TOBIAS, 2010, p.198).
\end{abstract}

A audiodescrição será inserida nos espaços entre as falas, com cuidado para não sobrepor aos diálogos dos personagens, a uma letra de uma música, ou mesmo ao silêncio, por vezes fundamentais ao enredo. O excesso de informações pode confundir e atrapalhar a fruição da obra, o que aponta para a necessidade de se conhecer a obra e fazer escolhas essenciais de forma que a audiodescrição possa interagir com os outros estímulos da peça.

Como se observa, o recurso permite que a pessoa desprovida da visão crie suas próprias interpretações ou suposições sobre o que viu, compartilhe comentários com outras pessoas videntes ou não, corroborando com a interação social, inclusão e apreciação mais prazerosa.

O estímulo visual é uma das principais vias de acesso ao mundo, por meio dele conhecemos o ambiente ao nosso redor, podemos identificar padrões corporais, sociais, 
relacionar conceitos e emoções. Ver significa sentir, observar e conhecer o mundo através das imagens.

Para as crianças com e sem deficiência visual, as experiências com o mundo envolvem o meio familiar, escolar, as potencialidades da criança, a tolerância à frustração, seu contato com outras crianças e adultos, os estímulos recebidos dos ambientes nos quais convive, a curiosidade, capacidade para aprender e enfrentar dificuldades e limitações. Esses aspectos contribuem para a formação do indivíduo, independente da sua deficiência.

Na mesma perspectiva, Masini (2003) afirma que:

É, pois, da reflexão sobre o vivido e da atenção à experiência perceptiva que emergem os significados da pessoa no mundo. Assim, por exemplo, a reflexão da criança com deficiência visual surge da sua experiência de habitar o mundo por meio de sua apalpação tátil, em que interroga o objeto de forma mais próxima do que se fizesse com o olhar (MASINI, 2003, p.41).

Em um mundo onde as imagens são predominantes, principalmente para se comunicar, o indivíduo que não enxerga se utilizará ainda mais dos outros sentidos para experienciar, interpretar e ressignificar suas vivências, de maneira a contribuir para a sua autonomia e a construção de novos conhecimentos.

A escola também é um lugar importante, fonte de novas descobertas, onde a criança aprende a ler, escrever, se comunicar e se relacionar fora do ambiente familiar com outras crianças e professores.

Nos livros didáticos, as imagens podem fornecer informações que nem sempre se encontram no texto. Segundo Motta (2016), em um livro de história, por exemplo, as imagens podem revelar informações sobre a época, costumes, vestuário, o que permite que o aluno faça uma comparação com a atualidade e observe as mudanças. A descrição das imagens, observando expressões gestuais, dos códigos visuais inseridos em um contexto social são importantes para a compreensão de mundo, dos signos determinantes em cada cultura.

Os filmes, as peças teatrais e a arte de forma geral são estimulantes meios de interação com a cultura, e possibilitam o desenvolvimento de conceitos críticos, ampliando o discernimento em relação aos acontecimentos do cotidiano e o conhecimento do mundo.

Neste aspecto, a arte e a atuação como atriz proporcionaram à pesquisadora vivências positivas na infância e adolescência, e uma profissão na vida adulta. Quando criança, as idas ao cinema, para assistir aos filmes inesquecíveis dos "Trapalhões", dentre outros, nas salas sempre lotadas, foram determinantes não somente para divertimento, mas até para garantir uma maior interação com os demais colegas no ambiente escolar, onde todos comentavam sobre o filme.

Depois de adulta, o interesse pela atuação levou a pesquisadora ao curso de teatro no centro cultural da cidade e de lá seguiu mais tarde para o curso técnico profissionalizante de ator no Teatro Escola Macunaíma. Atuar nos palcos era uma possibilidade de interpretar um personagem e contar sua história para uma grande plateia de espectadores atentos. Os primeiros espetáculos foram peças infantis, que exigiam uma maior dedicação, afinal o público infantil era um dos mais honestos e generosos, se não apreciava, falava e reclamava, mas se era prazeroso, a participação e risos era garantida.

Podemos afirmar, desta forma, que as experiências na fase infantil auxiliaram nas escolhas do futuro e ainda reverberam em situações do cotidiano. Já a formação em artes cênicas favoreceu à pesquisadora um olhar de dentro desse universo. Atualmente trabalho 
como audiodescritora, elaborando roteiro e fazendo narrações, atuo também como atriz e posso, com isso, observar detalhes e as maneiras de realização da arte, o que me auxilia nas escolhas de palavras, no meu trabalho de tradução das imagens em palavras.

A criança desenvolve a linguagem por meio da repetição e observação, ela associa imagens a palavras e aprende seu significado. Segundo Motta, "a visualização dos elementos imagéticos precede a palavra e ajuda no entendimento da própria palavra".

Portanto, a audiodescrição incluída no contexto escolar se transforma em uma ferramenta potencializadora da inclusão, de acesso à informação e ao mundo das imagens. Ler imagens pode contribuir "para a formação de alunos mais críticos, mais capazes de compreender os aspectos culturais, históricos e sociais contidos nas informações visuais" (MOTTA, 2015. p.22).

Enfim, o recurso é um potente instrumento para auxiliar crianças e adultos com deficiência visual no entendimento das imagens tão presente no cotidiano, ampliando seu repertório cultural, enriquecimento simbólico e, principalmente, sentimento de pertencimento ao mundo em que vive.

\section{Metodologia}

Este é um estudo descritivo de abordagem qualitativa, relatando as etapas de elaboração da audiodescrição (AD) do desenho animado "Peppa Pig". Descrevendo o desenvolvimento do roteiro de $\mathrm{AD}$, a consultoria feita por consultor com deficiência visual, a gravação, mixagem, finalização do desenho e elaboração de materiais táteis para exibição do desenho para as crianças com deficiência visual na escola CIADEVA em São Paulo.

Os sujeitos da pesquisa foram três crianças com deficiência visual com idades entre 5 e 9 anos, estudantes da escola na escola CIADEVA. Os instrumentos de coletas de dados foram a observação e questionários direcionados as crianças após a exibição do desenho animado.

\section{Audiodescrição do desenho animado peppa pig}

O desenho infantil Peppa Pig destinado às crianças na idade pré-escolar, que estão na fase de alfabetização, aprendendo palavras e desenvolvendo a linguagem, mostra a história da protagonista Peppa com sua família. Cada episódio, com duração máxima de cinco minutos, revela o dia a dia de Peppa, uma porquinha de 5 anos, em suas brincadeiras com o irmão, amigos e seu relacionamento com os pais e avós. $\mathrm{O}$ desenho dublado tem um narrador que comenta algumas ações e sentimentos dos personagens, visando uma aproximação e explicação do desenho, com uma linguagem simples destinada às crianças. Foram escolhidos 9 (nove) episódios aleatoriamente do DVD "Poças de Lama" adquirido em uma loja de departamento.

Após assistir aos episódios, o roteiro foi elaborado, elencando as informações visuais não verbais e as informações visuais verbais importantes para o entendimento. Como os personagens principais da história possuem características físicas iguais, descrevi as informações comuns a todos e depois as descrições específicas de cada um, repetindo uma ou outra característica para ajudar na construção da imagem. 
Optou-se por descrever com detalhes os personagens principais na apresentação do desenho, para que a criança pudesse criar uma imagem dos personagens anterior à história, garantindo um melhor aproveitamento dos espaços entre as falas, nos quais se privilegiava as informações de cada história. O essencial é que a criança entenda a história recebendo as informações das ações (gestual, roupas, expressões) no momento em que aparecem, sem excessos e de forma objetiva. Desta maneira, ela tem tempo para absorver esses elementos visuais da audiodescrição e interpretá-los associando às falas dos personagens, aos ruídos, silêncios e à música.

No roteiro de audiodescrição, inserimos as informações da audiodescrição entre os intervalos das falas, com as observações para a narração e posteriormente edição e mixagem do e desenho. Sugere-se no roteiro que a frase seja narrada mais rápida ou devagar, especificando o tempo exato no time code, no qual ocorre a fala dos personagens e onde será inserida a narração e audiodescrição, inserida em caixa alta.

Time code 13:47: Vovó: Minha nossa!

Time code 13:50: (Rápido) TODOS ARREGALAM OS OLHOS SURPRESOS.

Time code 23:12: Papai: Muito bem Peppa! Você é muito boa detetive.

Time code 23:16: (Rápido) ELA ABRE OS BRAÇOS E FECHA OS OLHOS ORGULHOSA.

Neste caso, descreve-se a expressão facial sugestionando sobre o que o personagem está expressando. Se descrevêssemos de outra maneira, apenas informando as expressões: "TODOS ARREGALAM OS OLHOS"; ou "ELA ABRE OS BRAÇOS E FECHA OS OLHOS", a criança poderia entender a ação de maneira difusa. Portanto, é preciso observar se no contexto da cena apenas esta descrição auxiliaria no entendimento e se o narrador fornece informações que completam a ação. Do contrário, pode nos suscitar muitas interpretações gerando ambiguidade.

Outros aspectos importantes do roteiro foram às escolhas lexicais utilizando palavras simples e dentro do gênero infantil do desenho animado como: "DÁ PULINHOS; CONHEÇA A HISTORINHA; DUAS ORELHINHAS COM PONTAS OVAIS; OS RABINHOS SÃO ENROLADOS E OS BRAÇINHOS FINOS E CURTOS; UMA CASINHA COM MUITAS JANELAS; AS LÁGRIMAS SALTAM DOS OLHOS DELE; APONTA PARA A BARRIGA DO PAI".

As escolhas lexicais em um roteiro de audiodescrição são determinantes para o entendimento. Uma palavra muito complexa pode dificultar uma apreciação do desenho ou produto audiodescrito. Uma palavra não usual no contexto infantil, "pode fazer com que o ouvinte perca o entendimento da história" (HYKS, 2005. p. 3). No caso de crianças em fase de alfabetização, a fluidez fica comprometida e o entendimento da imagem descrita incompreensível.

\section{A consultoria do roteiro de audiodescrição}

A consultoria do roteiro é uma parte importante do processo de audiodescrição. O consultor deverá ter um bom conhecimento da língua portuguesa, ser um observador criterioso, curioso, conhecer sobre as normas da audiodescrição e elaboração de roteiros. O consultor é uma pessoa com deficiência visual, usuária da audiodescrição, que contribuirá 
para uma revisão assertiva sugerindo alterações no roteiro e na narração que vão garantir a qualidade e apreciação pelo usuário final.

Encaminhei para a consultora em audiodescrição, Cristiana Cerchiari, os vídeos dos episódios do desenho finalizado com audiodescrição inserida e o roteiro em arquivo Word. Assim que a consultora assistiu aos episódios do desenho, enviou-me via e-mail uma mensagem, comentando sobre sua apreciação pela audiodescrição.

Primeiro, assisti aos desenhos, e só depois disso li o roteiro de AD. Adorei tudo! O narrador do desenho "ajuda" o audiodescritor, e você parece ter se divertido fazendo a locução do roteiro de AD. Parabéns pela escolha do tema! Enquanto pensava no seu trabalho, lembrei-me de ter me sentido muito excluída culturalmente na infância. Os desenhos de que eu mais gostava eram os que tinham mais diálogos, ou seja, quase nenhum.

As palavras da consultora Cristiana comprovam a relevância deste estudo para o público infantil, muitas vezes excluído do acesso a produtos culturais. A consultora refere-se ao narrador do desenho animado "Peppa Pig", que tem a função na história de informar, enunciar e detalhar alguma informação sobre o ambiente, personagens ou ações. Neste caso, a audiodescrição considera essas informações descrevendo a imagem complementando o entendimento e com fluidez dentro do contexto do desenho.

\author{
Time code 39:27 - Narrador: A Peppa e sua família vão acampar. \\ Time code 39:28 - Papai: Eu adoro acampar. \\ Time code 39:32 - O CARRO DA FAMÍLIA PIG COM MALAS E BARRACA NO \\ BAGAGEIRO ESTACIONA. \\ Time code 39:40 - Papai: Peppa, George esta é minha tenda desde que eu era \\ garoto. \\ Time code 39:43 - (Rápido) ELE VIRA O SACO DA BARRACA. \\ Time code 40:08 - Narrador: Os pinos sustentam a barraca.
}

Nos trechos retirados do roteiro de audiodescrição, observamos as informações sobre o ambiente, um acampamento e as características de objetos utilizados pelos personagens, como os pinos da barraca.

Conforme as orientações da consultoria utilizaram-se o tempo verbal no presente ou presente contínuo e a alteração da palavra "tenda" para "barraca", que é mais usual e de fácil compreensão para crianças. Contudo, no desenho, o personagem do narrador utilizou também a palavra "barraca", enquanto os personagens utilizaram a palavra "tenda". A audiodescrição manteve a palavra "barraca" por ser uma palavra mais usual no contexto infantil facilitando o entendimento da imagem descrita.

\title{
Gravação da audiodescrição
}

Como no desenho a voz do narrador é masculina e presente o tempo todo durante as histórias, uma voz feminina para audiodescrição seria mais viável para diferenciar as 
narrações. A experiência como dubladora me auxiliou no uso adequado da voz e na postura no estúdio.

A audiodescrição é uma informação sonora adicional que transporta os conteúdos imagéticos em forma de texto transmitido pela voz, portanto, essa transmissão deve ser agradável, bem articulada para que seja compreendida.

Os estudos de (SILVA APUD CARVALHO, 2003) relatam a preferência por um estilo de narração mais dinâmico e interpretativo para crianças cegas ou com baixa visão. Tendo isto em mente, a gravação da narração foi realizada com um "sorriso" 1 na voz, denotando a animação da personagem quando pulava e se divertia. Esse aspecto da narração foi notado e aprovado pela consultora.

Ademais, na narração para crianças, o ritmo e a entonação ainda são mais importantes, pois irão estimular o interesse pelas imagens favorecendo a imaginação e desenvolvimento de suas próprias interpretações.

\section{Mixagem e finalização do áudio da audiodescrição}

A mixagem da audiodescrição foi realizada por um editor de som, que inseriu o áudio da narração de $\mathrm{AD}$ no desenho guiado pelo roteiro. $\mathrm{O}$ editor precisa entender o que é a audiodescrição e inseri-la dentro dos espaços informados pelo Time Code juntamente com o som original do desenho.

Por orientação do consultor, foram realizados ajustes de volume no som da audiodescrição, pois em alguns trechos o volume da narração estava alto, destacando-se mais do que as falas dos personagens e em outros momentos o som baixo dificultava o entendimento. $\mathrm{O}$ som da $\mathrm{AD}$ deve ser equivalente aos diálogos do desenho oferecendo uma boa qualidade sonora, auxiliando assim na fluidez e apreciação com qualidade do desenho.

\section{A exibição do desenho na escola para crianças com deficiência visual}

A exibição do desenho fora marcada com antecedência com diretora da Ciadeva Centro de Integração e Apoio ao Deficiente Visual e Auditivo, localizada no Estado de São Paulo. A escola promove o ensino e inclusão de crianças com deficiência auditiva e visual, com profissionais capacitados para o atendimento e ensino de crianças com tais deficiências.

$\mathrm{Na}$ chegada à instituição, os professores mostraram-se interessados, acompanhando a pesquisadora na visita e apresentando outras turmas de alunos com deficiência visual e auditiva. A receptividade favoreceu um ambiente agradável e acolhedor para realização da exibição do desenho.

A escola, estruturalmente simples, tem salas pequenas de aproximadamente $3,25 \mathrm{~m} \mathrm{x}$ $2,60 \mathrm{~m}$, dificultando um pouco uma projeção ampliada do desenho. Compareceram para exibição (2) dois professores e (3) alunos com deficiência visual, acompanhados de outros (3) três profissionais da escola, incluindo a coordenadora e outros professores videntes. Uma

\footnotetext{
1 "Sorriso" refere-se a qualidade da narração, com mais alegria e empolgação da voz da narradora de audiodescrição percebido pelo ouvinte.
} 
professora sugeriu exibir o desenho sem a imagem, apenas com o som da narração de audiodescrição para as crianças com deficiência visual. No entanto, a pesquisadora orientou que a imagem seria importante para os videntes presentes, como professores e para os adultos e crianças com baixa visão.

Antes da exibição, a pesquisadora apresentou os personagens principais do desenho "Peppa Pig" por meio de material tátil confeccionado em EVA (Espuma Vinílica Acetinada) auxiliando na formação da imagem mental dos personagens através do estímulo tátil. As crianças e os presentes na sala foram convidados a tocarem nos personagens em EVA distribuídos sobre a mesa. Os adultos com deficiência visual acharam interessantes as características dos personagens, relatando não conhecer o desenho.

A exploração tátil fora mediada pela pesquisadora que descrevia cada característica como olhos, boca, orelhas, corpo juntamente com o toque da criança no personagem. Observou-se que a criança (L) abriu um sorriso, tateando os personagens e verbalizando algumas palavras da descrição informadas pela pesquisadora. Outra criança $(\mathrm{M})$ tocou nos desenhos auxiliada pela pesquisadora, sem esboçar questionamentos. Observamos uma ansiedade pela criança (L) para o início da exibição, devido a sua agitação na cadeira e repetição dos nomes dos personagens descritos anteriormente.

Durante a exibição do desenho animado, o aluno (L) balançou os braços e cantou baixinho a música da personagem Peppa que antecede cada episódio. Em vários, ouvimos comentários de uma professora dizendo: "não imaginava que era assim a audiodescrição, tantas informações para dizer mesmo com narrador". Outro professor, com baixa visão, comentou rindo: "Que desenho bonitinho da Peppa. Parece que estou vendo tudo".

Os comentários e comportamento dos alunos e professores reforçaram a importância da audiodescrição no desenho, mobilizando os profissionais e alunos, o conhecimento do recurso e uma possibilidade de atividade pedagógica a partir do desenho, sendo relevante para o estudo.

O questionário pós-exibição para as crianças continha perguntas relacionadas ao desenho e à experiência da exibição. A pesquisadora direcionou as perguntas para cada criança e anotou as respostas referentes à apreciação do desenho, a percepção de uma voz que descrevia e contava os detalhes da história. As crianças com deficiência visual verbalizaram pouco a respeito do desenho. Tal comportamento surpreendeu os professores, que alegaram um comportamento contrário delas em sala de aula.

Em resposta ao questionário, a criança (L) respondeu: "ela fica nas letras $\mathrm{P}$ e A", cantando posteriormente um trecho da música em tom baixo, referindo-se à cena do desenho em que a personagem principal, Peppa, fica entre as letras de seu nome.

Verificamos que a criança $(\mathrm{G})$, quando questionada sobre qual era a cor da Peppa, respondeu em tom quase inaudível no ouvido da pesquisadora: "rosa", denotando ter apreendido esta característica a partir da audiodescrição.

Notamos que os alunos com deficiência visual e alguns professores tiveram seu primeiro contato com a audiodescrição durante a exibição do desenho na escola. Efetivamente, não souberam elucidar sobre o recurso, no entanto, de certa maneira, este chamou a atenção deles para uma nova possibilidade de assistir a desenhos e acessar as imagens anteriormente inacessíveis pela ausência de visão.

Observamos nas sucintas respostas após a exibição do desenho Peppa Pig que a audiodescrição favoreceu o entendimento de alguns aspectos. Como a ação da personagem Peppa pulando das letras de seu nome e a característica física da cor de pele rosa mencionada pela criança $(\mathrm{G})$. 
Os professores com deficiência visual denotaram acessar os conteúdos imagéticos do desenho através da audiodescrição, comparando o recurso à percepção da visão.

A maioria das crianças demonstrou interesse durante a atividade com materiais táteis e exibição do desenho, repedindo informações e assistindo atenta. Desta maneira, mesmo o aluno (M) tendo apresentado um comportamento mais agitado, levantando por diversas vezes da cadeira, pôde acompanhar ao menos três episódios completos. Considerando que a atividade é relativamente nova no cotidiano escolar, percebe-se de maneira positiva a introdução da audiodescrição na escola.

\section{CONSIDERAÇÕES FINAIS}

A apresentação do desenho na escola favoreceu uma atividade de interação entre professora, alunos e pesquisadora. Os alunos e professores denotaram interesse no recurso e sentiram-se motivados e incluídos com o acesso as imagens do desenho.

As crianças precisam de experiências que auxiliem no aprendizado, desenvolvimento da linguagem e principalmente na interação como outro, seja ela com ou sem deficiência.

A vivência profissional como atriz e audiodescritora foi importante permitindo passar pelas fases do processo de audiodescrição, como a organização, produção do roteiro, narração e preparação da exibição e apresentação para crianças com desenvoltura e segurança.

A análise da realização de cada etapa foi fundamental para a produção de uma proposta de audiodescrição para desenhos animados, corroborando para os avanços nos estudos de audiodescrição de desenhos para público infantil com deficiência visual.

A audiodescrição é um caminho possível para acessibilidade em meios audiovisuais, como desenhos, filmes e precisa o quanto antes em mais programações televisivas ou das salas de cinema. Contudo, a vontade de promover acessibilidade e o contato com produtos audiovisuais para crianças foi fortalecida com esse trabalho.

A audiodescrição do desenho na instituição favoreceu a divulgação do recurso para professores e alunos possibilitando o acesso ao conteúdo imagético do desenho, conectandoos à cultura influindo positivamente na inclusão.

\section{REFERÊNCIAS}

ESTATUTO da criança e do adolescente (ECA). Lei 8.069 de 13 de julho de 1990. 13. ed. Brasília: Câmara dos Deputados, 2015.

HYKS, V. Audio Description and Translation. Two related but different skills. 2005.

MASINI, E. F. S. Experiência perceptiva é o solo do conhecimento de pessoas com e sem deficiências sensoriais. Psicologia em Estudo, Maringá, v. 8, n. 1, p. 39-43, jan./jun. 2003.

MOTTA, L. M. V. Audiodescrição: definições. Disponível em: http://vercompalavras.com.br/home. Acesso em: <09 de ago. de 2015>. 
MOTTA, L. M. V. Audiodescrição: Transformando Imagens em Palavras. São Paulo: Secretaria dos Direitos da Pessoa com Deficiência do Estado de São Paulo, 2010.

MOTTA, L. M. V. M. Audiodescrição na escola: abrindo caminhos para leitura de mundo. Editora Pontes: Campinas, 2016.

PROGRAMAÇÃO TV cultura. Peppa Pig. Disponível em: http://tvcultura.cmais.com.br/peppapig/index.php. Acesso em <20 d ago. de 2015>.

SILVA, M. C. C. C. Com os olhos do coração: estudo acerca da audiodescrição de desenhos animados para o público infantil. 214 f. (Dissertação Mestrado em Letras e Linguística) Universidade Federal da Bahia - Salvador, 2009.

WILSON, J. A. C.; MAGALHÃES, M. M. Locução em filmes audiodescritos para pessoas cegas ou com baixa visão: uma contribuição à formação de audiodescritores. In: ARAÚJO, V.L.S.; ADERALDO, M.F. (Org.). Os novos rumos da pesquisa em audiodescrição no Brasil. Curitiba, 2013, p.151-168.

Recebido em: 03/10/2019

Aprovado em: 05/12/2019 